\title{
The potential of mesenchymal stromal cells as a novel cellular therapy for multiple sclerosis
}

Multiple sclerosis (MS) is an inflammatory neurodegenerative disease of the CNS for which only partially effective therapies exist. Intense research defining the underlying immune pathophysiology is advancing both the understanding of MS as well as revealing potential targets for disease intervention. Mesenchymal stromal cell (MSC) therapy has the potential to modulate aberrant immune responses causing demyelination and axonal injury associated with MS, as well as to repair and restore damaged CNS tissue and cells. This article reviews the pathophysiology underlying $\mathrm{MS}$, as well as providing a cutting-edge perspective into the field of MSC therapy based upon the experience of authors intrinsically involved in MS and MSC basic and translational science research.

\section{KEYWORDS: experimental autoimmune encephalomyelitis IFN- $\gamma$ immunomodulation inflammation mesenchymal stromal cell multiple sclerosis Th17 cell Toll-like receptor transplantation}

Multiple sclerosis (MS) is a progressive neurodegenerative disorder of the CNS characterized by chronic inflammation, demyelination and neuronal damage [1]. Currently, there is no medical cure for MS, mainly owing to an incomplete understanding of its pathophysiology. Animal models of experimental autoimmune encephalitis (EAE) have mechanistically defined the inciting and perpetuating immune processes responsible for the clinical manifestations and evolution of MS [2]. This insight has resulted in the application of immunotherapy to treat MS [3]. However, conventional immunotherapy used in other diseases has the potential to worsen clinical disease and increase the risk of infection [4]. Therefore, novel therapies that can potentially modulate aberrant immune responses and mediate restorative effects to damaged neuronal tissue would be ideal for treating MS (Figure 1).

Mesenchymal stromal cells (MSCs) are multipotent, nonhematopoietic cells that possess both immunomodulatory and regenerative properties [5]. Most commonly isolated from bone marrow (BM), MSCs have also been isolated from numerous tissues including adipose tissue, umbilical cord blood [6], placenta [7], thymus [8] and dental pulp [9]. Regardless of source, MSC designation requires the following minimal criteria:

- Plastic-adherent in vitro expansion;

- Absence of hematopoietic surface markers CD14, CD11b, CD19, CD34, CD45 and HLA-DR, and presence of surface markers CD73, CD90 and CD105;
- In vitro differentiation into adipocytes, chondroblasts and osteoblasts [10].

The allure for using MSCs as novel cellular therapy arises from their ease in expansion, safe infusion profile and demonstrated immunosuppression, particularly in the setting of alloreactivity such as graft-versus-host disease (GvHD) as reviewed in Auletta et al. [11]. MSCs have also recently been proposed as treatment for autoimmune diseases such as MS [12,13], particularly given their putative roles in immunosuppression and neural repair (Figure 1) [14]. MSC immunosuppressive function may be enhanced through stimulation by Toll-like receptor (TLR) agonists [15] and IFN- $\gamma$ [16]. TLRs are also emerging as treatment targets for MS-associated autoimmunity [17]. Similarly, IFN- $\gamma$ plays an important role in immune-mediated CNS insult in EAE models [18]. This article critically reviews the use of MSC therapy for MS with emphasis on:

- Mechanisms underlying the clinical manifestations of MS, as defined by preclinical models, which ultimately are targets for the therapeutic effects of MSCs;

- Contributions of TLR signaling and IFN- $\gamma$ induction to MS pathophysiology, as well as the potential of TLR ligands and IFN- $\gamma$ to enhance MSC-mediated immunosuppression in MS;

- Application of cellular therapy, in general, for MS and how MSCs, in particular, are being incorporated in one of the first leading clinical trials as novel MS therapy.

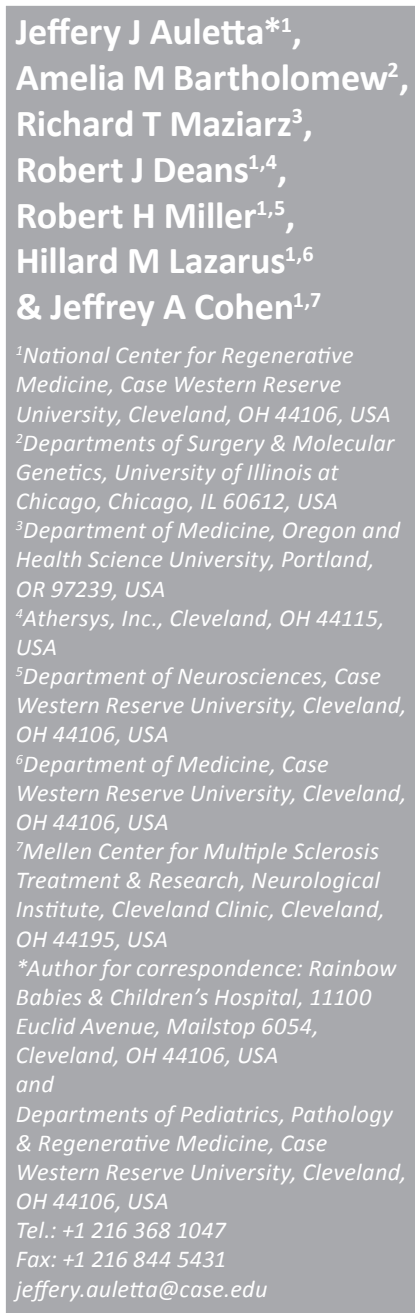

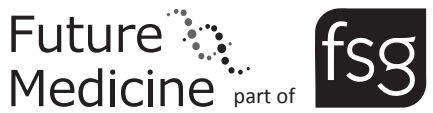




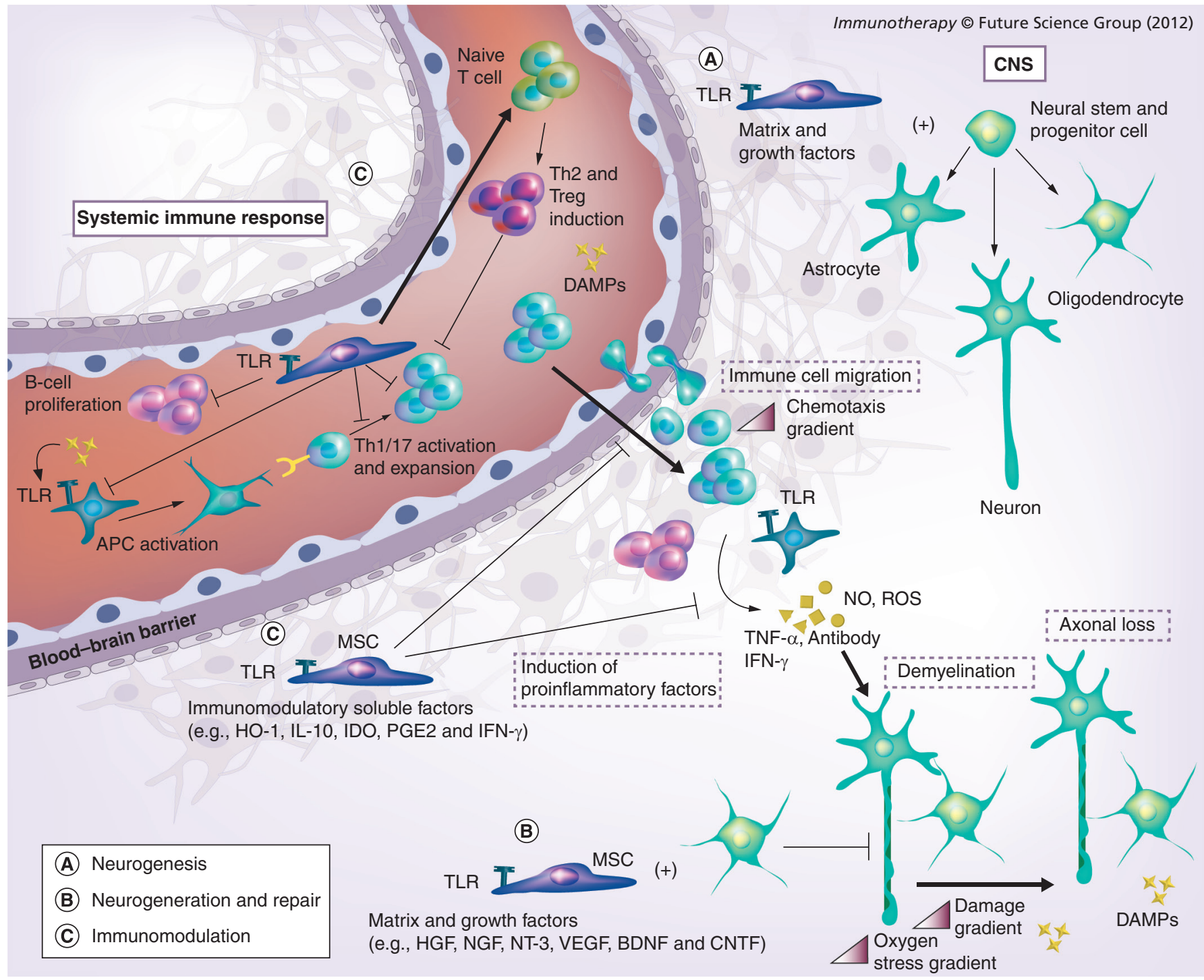

Figure 1. Putative roles for mesenchymal stromal cells in multiple sclerosis. Proposed mechanisms underlying the pathophysiology of multiple sclerosis are mainly extrapolated from murine EAE models, wherein instigating signals for autoimmune-mediated proinflammation arise from either autoreactive lymphocytes in the body ('systemic immune response') or damage gradients caused by oligodendroglial and axonal degeneration within the CNS. Specifically, TLRs recognize both DAMPs and PAMPs and activate innate immune cells to produce proinflammatory cytokines and chemokines, and to serve as potent APCs for naive $T$ cells. Subsequent activation and expansion of proinflammatory Th1 and Th17 cells and their soluble factors increases chemotaxis gradients, ultimately resulting in their emigration into the CNS. Cytokines (TNF- $\alpha$ and IFN- $\gamma$ ), autoantibodies and hypoxia-inducible factors including NO and ROS cause demyelination and ultimately axonal injury/loss. In addition, damage to myelin and axons can also induce proinflammatory damage gradients, which can activate innate and adaptive immune cells in the CNS to release neurotoxic soluble factors. Proposed effects of MSCs include (A) neurogenesis, (B) regeneration and repair of myelin and axons, and (C) downmodulation of the systemic and CNS inflammatory response. Pathologic processes underlying multiple sclerosis pathophysiology are illustrated as dashed boxes, and proposed effects of MSCs are labeled with encircled bold letters. Refer to the main text for references.

DAMP: Damage-associated molecular pattern; EAE: Experimental autoimmune encephalitis; HO-1: Heme-oxygenase 1; IDO: Indoleamine 2,3-dioxygenase; MSC: Mesenchymal stromal cell; NO: Nitric oxide; NT-3: Neurotrophin 3; PAMP: Pathogen-associated molecular pattern; ROS: Reactive oxygen species; TLR: Toll-like receptor.

\section{Animal models of MS: advancing an understanding for MSC effects}

Several animal models have been developed that reflect distinct aspects of MS pathology. The best known and most commonly used model is EAE [19]. In this model, injection of a myelin immunogenic peptide in combination with an adjuvant leads to widespread inflammation and variable demyelination in the brain and spinal cord. Depending on the nature of the peptide and the genetic background of the host animals, the resulting functional deficits may result in either a relapsing-remitting 
disease, similar to that seen in early MS, or a more chronic disease as seen in later stages of MS. This model has been very effective at dissecting the immunological basis of the functional deficits and has provided insight into potential therapeutic approaches, including the use of TLR agonists and antagonists in EAE $[17,20]$. In general, in both relapsingremitting EAE, stimulated by PLP epitopes on a $S J L$ background and in chronic EAE, stimulated by MOG peptides on a C57BL6 background, the major immune effector cells appear to be autoreactive Th1 cells, Th17 cells and myeloid APCs [21]. These cell types coordinate the production of inflammatory cytokines and chemokines within the CNS parenchyma [22], leading to the recruitment of macrophages, mast cells, neutrophils, CD8 ${ }^{+}$ $T$ cells and B cells, which subsequently target components of the myelin sheath and axons (Figure 1). Therapeutic interventions that regulate the immune response have been shown to be effective in the treatment of EAE.

Other models of demyelinating diseases facilitate the analysis of aspects of remyelination in the absence of ongoing inflammation. Local demyelinating lesions generated in response to the local injection of gliotoxins such as ethidium bromide or lysophosphatidylcholine are the best developed [23]. While these models lack the inflammatory components that characterize MS, they provide relatively well-defined models to assess the mechanism of remyelination in the intact CNS. Such studies have identified distinct stages in the process of demyelination and remyelination. During the formation of the initial lesion, there is a loss of oligodendrocytes and their precursors, oligodendrocyte precursor cells (OPCs), in the region of injury. With a diminution of the pathogenic process, OPCs invade the demyelinated region and undergo a proliferative response. These cells then differentiate into mature oligodendrocytes and target denuded axons around which they reform myelin sheaths. Myelin sheaths that are formed during the remyelination process are thinner than the original sheaths and may enwrap a shorter axonal segment. Each of these distinct steps represents a potential point of failure in remyelination, and effective therapies resulting in long-term functional recovery will need to facilitate multiple aspects of the remyelination program [23]. MSCs appear to be effective agents in modulating both immune pathogenic processes [24] and enhancing remyelination in animal models of demyelination (Figure 1) [25].

\section{Effects of mouse MSC treatments in murine models of MS}

Long-term functional recovery in demyelinating diseases requires regulation of the pathogenic process modulated by MSCs in several different animal models of CNS demyelination [26]. For example, systemic transplantation of autologous or allogeneic mouse MSCs in relapsingremitting [27], or chronic progressive models of EAE [28], induced a state of tolerance in the immune response, leading to clinical improvements. Animals with EAE that received an intraventricular infusion of MSCs had a significantly reduced disease burden that was associated with downregulation of activated $\mathrm{T}$ cells and induction of T-cell anergy [28], suggesting that a primary effect of murine MSCs is induction of immunosuppression. The concept that MSCs induce immunosuppression in these models is consistent with findings in other disease settings and with the suggestion that other adult stem cells share this characteristic [29].

\section{Effects of human MSC treatments in murine models of MS}

With the development of clinical trials utilizing MSCs in the treatment of MS, it becomes critical to determine whether the functional properties of human MSCs are similar in the murine systems outlined above. In this regard, we [25] and others [26] have undertaken a series of studies designed to assess the influence of BM-derived human MSCs (hMSCs) on disease progression in animal models of immune-mediated demyelination. These studies provide strong evidence that murine MSCs and hMSCs share functional properties despite their well-recognized differences [30]. For example, transplantation of hMSCs into animals with ongoing EAE results in a rapid and sustained functional recovery [25], suggesting that these cells alter several aspects of disease progression including modulation of T-cell activities. As a result, similarly to their murine counterparts, hMSCs exert an immunoregulatory effect $[27,31]$. Although the mechanisms mediating hMSC effects are still only partially understood, they probably involve both cell-to-cell contact and soluble factors.

\section{- Defining mechanisms of action of MSCs in EAE}

Influence of MSCs on the murine immune system

Treatment of animals with ongoing EAE with either murine MSCs or hMSCs has profound effects on the relative numbers of pro- and 
anti-inflammatory cells [25]. Following treatment with human BM-derived MSCs in MOGinduced EAE, the relative frequency of IFN- $\gamma$ producing splenocytes was significantly reduced, while the relative frequency of IL-4-producing cells was increased. Similar trends were seen in the PLP ${ }_{139-151}$ EAE model, suggesting that MSCs reduce inflammatory myelin-specific Th1 cells and increase inflammatory-inhibiting Th2 cells in EAE [25]. Consistent with these results, in vitro peptide stimulation of spleen cells from $\mathrm{MOG}_{35-55}$ EAE animals enhanced levels of cytokine induction, including IFN- $\gamma$, IL-17, IL-2, IL-12p70, TNF- $\alpha$, IL- 4 and IL-5. In MSC-treated animals, the average levels of inflammatory Th1/Th17 cytokines (IFN- $\gamma$, IL-17, IL-2, IL-12p70 and TNF- $\alpha$ ) were significantly reduced, while the levels of anti-inflammatory Th2 cytokines (IL-4 and IL-5) were significantly increased [25]. Importantly, one of the most downregulated cytokines was IL-17, a molecule that is strongly implicated in mediating the progression of disease in EAE [32]. Splenocytes from $\mathrm{MOG}_{35-55}$-induced EAE animals challenged in vitro with $\mathrm{MOG}_{35-55}$ demonstrated a robust proliferative response. By contrast, cells derived from MSC-treated animals showed little or no proliferative response upon antigen challenge. Additionally, colony-forming assays demonstrated a reduction in colonyforming cells in MSC-treated EAE animals [25]. Together, these studies suggest that MSCs induce a state of myelin antigen-specific T-cell unresponsiveness that may contribute to the functional benefit seen following MSC treatment.

\section{Influence of MSCs on murine neural cells}

Several lines of evidence from animal studies suggest that the beneficial effects of MSCs in demyelinating diseases are not limited to modulation of the immune response, but may also reflect a more direct influence of MSCs on neural cell responses in the setting of CNS insults (Figure 1). The existence of neural stem cells in the adult vertebrate CNS is now well established [33], and these cells are thought to contribute to ongoing neurogenesis in specific regions of the CNS and to contribute towards CNS repair [33]. An effective model with which to study neural stem cells is the neurosphere approach pioneered by Reynolds and Weiss [34]. When neurospheres were generated from animals with ongoing EAE, the majority of the cells that develop in vitro were astrocytes, recognized by the expression of GFAP, while the number of oligodendrocytes, OPCs and neurons were relatively limited [25]. By contrast, in MSC-treated EAE animals, the proportion of oligodendrocytes and neurons was substantially increased and the number of astrocytes reduced [25]. Since astrocytes have been proposed to inhibit repair in CNS insults [35], and oligodendrocytes and OPCs are required for regeneration following demyelination, these studies suggest that the functional improvement mediated by MSCs in EAE may reflect enhancement of endogenous repair processes. In support of this, histological analyses of MSC-treated EAE animals showed increases in the number of oligodendrocytes, enhanced remyelination and improved axonal integrity in lesion areas containing MSCs, consistent with MSCs supporting enhancement of neural repair [25].

The concept that MSCs may modulate neural responses in the setting of CNS demyelination has been raised in several studies. For example, endogenous neural stem or progenitor cells are activated by MSCs [36] and BM stromal cells have been shown to promote neurogenesis in the hippocampus [36]. In EAE, treatment with MSCs resulted in almost twice the number of spared axons in lesion areas compared with control mice [37]. One early notion was that, with appropriate stimuli, MSCs may be capable of differentiating into nonmesenchymal lineages, including endothelial [38] and neural cells [39]. Whether this reflects transdifferentiation, ectopic marker expression or cell fusion is currently unclear [40]. However, in studies using labeled MSCs, little evidence for the transplanted cells assuming a neural fate was found [25]. Perhaps more importantly, several studies have shown that MSCs provide soluble cues that influence fate choices in neural cells, rather than directly generating neural cells [41].

Continued mechanistic studies available through the use of animal models of MS will allow for a detailed characterization of the role of these cells in neural repair. Identification of the mechanisms underlying the functional recovery will probably facilitate the selection of MSCs that provide the most effective therapies in demyelinating diseases such as MS, as reviewed below. Lastly, mechanistic-driven studies may elucidate ways to exploit the therapeutic benefit of MSC therapy in MS.

\section{Translating preclinical observations into therapeutic platforms: novel experimental directions for MSC therapy using TLR and IFN- $\gamma$ activation \\ Toll-like receptors}

TLRs are pattern recognition receptors expressed on both hematopoietic (e.g., innate and adaptive 
immune) and nonhematopoietic (e.g., epithelium and endothelium) cells that recognize inducible pathogen-associated molecular patterns and danger-associated molecular patterns (DAMPs) following infectious and injurious insult to the host [42]. TLR ligands activate MyD88-dependent and -independent signaling cascades within immune cells that ultimately activate NF-KB and MAPKs to synthesize proinflammatory cytokines and chemokines [42]. TLR expression itself reflects cytokines and other factors within the microenvironment that can upregulate TLR expression and enhance immune cell migration and cytokine production $[43,44]$. For example, TLR4 activation upregulates surface expression of adhesion and costimulatory molecules on immature dendritic cells, changing their function from antigen-capturing and -processing cells to potent APCs that migrate to secondary lymphoid organs and stimulate naive $T$ cells, activating an adaptive proinflammatory response [45]. In this regard, TLRs critically link innate and adaptive immune responses [46]. Finally, TLR signaling also activates damage-induced inflammatory pathways, including oxygen stress response and cellular damage/necrosis. Reactive oxygen species induce cellular necrosis and the release of cytoplasmic and nuclear materials that function as DAMPs and signal through TLR2, TLR4 and RAGE [47]. DAMPs such as HMGB1, which signals through TLR2 and TLR4, are highly expressed in MS and EAE lesions, indicating a direct role in MS pathophysiology [48].

TLR-dependent T-cell activation is a known catalyst for autoimmune inflammation [49]. Autoimmune-mediated chronic inflammation causes the deleterious effects of demyelination as well as axonal injury and loss associated with MS (Figure 1). Specifically, activated monocytes/macrophages and Th1 and Th17 cells cause oligodendroglial damage and axonal loss through both direct (e.g., myelin phagocytosis) and indirect (e.g., production of soluble factors such as nitric oxide and reactive oxygen species) effects [50,51]. However, the inciting signals in MS that initiate autoimmune-related inflammation and ultimately the breakdown in immune tolerance remain largely undefined. Pathogens including viruses have been proposed as candidate antigens for initiating host autoimmunity [52,53]. Given their pivotal roles in linking pathogen- and damage-induced inflammation, as reviewed above, TLR ligands (DAMPs and pathogen-associated molecular patterns) that function as either autoimmune activating or dampening signals in MS [54] are currently being investigated as a targeted therapy for MS [17]. For example, TLR3 stimulation has been shown to protect against MS through induction of type I interferons [55]. Therefore, synthetic TLR3 agonists, including CQ-07001, are currently under preclinical investigation as potential treatment for EAE. By contrast, antagonists against TLR2, TLR4 and TLR9, as well as MyD88, are being studied as these TLRs and adaptor proteins have proinflammatory effects in MS progression (reviewed in Gambuzza et al. [17] and summarized in TABLE 1).

MSC immunomodulation has largely been defined using in vitro culture conditions [56], wherein MSCs have been shown to influence innate and adaptive immune cell activation,

\begin{tabular}{|c|c|c|c|}
\hline $\begin{array}{l}\text { TLR } \\
\text { (synthetic ligand) }\end{array}$ & Human TLR mRNA expression & TLR effects in EAE & Human MSC effect on immune response \\
\hline MyD88 & NA & Enhances $[155,156]$ & NA \\
\hline TLR2 (Pam ${ }_{3}$ Cys) & $\begin{array}{l}\text { Microglia [70] } \\
\text { Astrocytes [71,157] }\end{array}$ & $\begin{array}{l}\text { No effect }[155] \\
\text { Enhances }[158,159]\end{array}$ & No change in T-cell activation $[160,161]$ \\
\hline TLR4 (LPS) & $\begin{array}{l}\text { Microglia [70] } \\
\text { Astrocytes [71] }\end{array}$ & Enhances [156,159,163] & $\begin{array}{l}\text { Stimulates T-cell activation }[68,162] \\
\text { Suppresses T-cell activation }[15] \\
\text { Enhances MSC migration [69] }\end{array}$ \\
\hline
\end{tabular}


development and function [57,58], mainly through production of modulatory soluble factors (FIGURE 1) [59]. In this regard, MSC suppression of Th1 and Th17 activation, proliferation and function [60], as well as induction of Tregs [61], seems most relevant to MS pathophysiology. Although in vivo MSC effects on T-cell activation and function remain limited to preclinical studies [62], such studies provide insights into how TLRs and their ligands may function to direct MSC immune response [63]. Specifically, TLR ligands can affect MSC differentiation, activation and immune function [64,65], particularly in the context of infection [66], as well as immunemediated disease [67]. For example, TLR3 and TLR4 priming have recently been shown to modulate MSC function, changing MSCs from proinflammatory (TLR4-primed) to immunosuppressive (TLR3-primed) cells [68], and further suggesting that MSCs possess an inherent plasticity in immune function that is influenced by their ability to respond to TLR agonists in the microenvironment [69]. In addition, TLRs are also expressed on neural cells [70-72], and so TLR ligation can directly influence neurogenesis and neural cell function within the CNS niche. As a result, the proposed proinflammatory microenvironment in MS, which contains TLR ligands and TLR-inducible soluble cytokines and chemokines, can have profound effects on MSC immune function (reviewed in Auletta et al. [11]), as well as regenerative capacity [73] in ameliorating aberrant immune responses and repairing damaged neuronal tissue.

TABLE 1 summarizes the emerging roles of TLR ligands and signaling in human neurogenesis, in preclinical EAE pathophysiology and in human MSC-mediated immunity. Focus is placed on TLR ligands (TLR3, TLR4 and TLR9) and signaling (MyD88) with effects studied across these three spectra. As discussed above, the use of TLR agonists or antagonists to direct in vivo immune responses associated with MS may have profound consequences in modulating activation and function of both immune cells and MSCs (Figure 1).

\section{IFN- $\gamma$ activation}

Following administration, ex vivo-expanded MSCs can migrate to numerous tissues and organs within the body and are particularly attracted to sites of inflammation [74,75]. Equipped with TLRs, MSCs can expertly interact with and respond to inflammatory milieus containing IFN- $\gamma$ and TNF- $\alpha$, as discussed above. However, direct exposure to IFN- $\gamma$ and
TNF- $\alpha$ themselves can cause MSCs to release a plethora of growth factors and cytokines involved in self-tolerance and tissue regeneration $[76,77]$, as well as chemotaxis of other cell types involved in neurologic protection and repair $[78,79]$.

The scale of the anti-inflammatory MSC response appears to reflect the magnitude of inflammation encountered. Exposure to low levels of IFN- $\gamma$ can stimulate the immune response by permitting MSCs to serve as APCs, an activity that disappears with higher IFN- $\gamma$ levels $[80,81]$. With increased IFN- $\gamma$ exposure, MSCs correspondingly increase their suppression of lymphocyte proliferation, in part owing to indoleamine 2,3-dioxygenase-mediated tryptophan depletion [82]. Increases in MSC production of anti-inflammatory cytokines COX-2, PGE2, TGF- $\beta 1$ and HGF may also provide a dose-response effect [76]. Likewise, the in vivo function of MSC-mediated immunity is also affected by the magnitude of IFN- $\gamma$ exposure, as demonstrated by the ability of MSCs to prevent GvHD [83]. Furthermore, ex vivo exposure of MSCs to low levels of IFN- $\gamma$ were ineffective, while high IFN- $\gamma$ levels $(\geq 500$ units/ml) were sufficient in preventing GvHD. In a study of lupus-diseased mice, BM-derived MSCs were observed to reduce glomerular damage based upon an IFN- $\gamma$-dependent effect [84]. While MSCs affected B-cell activation of both follicular and marginal zone B cells from lupus mice, they did not affect the production of autoantibodies or the mortality rates, suggesting that the magnitude of inflammation in vivo was not sufficient to maximize MSC anti-inflammatory effects. A similar observation was reported in the collagen-induced arthritis model, which demonstrated an ex vivo IFN- $\gamma$-dependent antiproliferative effect, but no in vivo beneficial effect in mitigating arthritis [85]. Together, these findings support the notion that MSCs can exert a spectrum of immunoregulation, ranging from proto anti-inflammatory, based upon sensing cues from the microenvironment $[63,66]$. Therefore, directing MSC function to preferentially promote an optimal anti-inflammatory effect might be best achieved with controlled ex vivo exposure to IFN- $\gamma$ prior to systemic administration.

MSCs can exert proregenerative effects by recruitment of alternatively activated macrophages, by endothelial cells and by enhancing vascularity $[86,87]$, all of which can be important in both neuroprotective and neuroregenerative activities. Proregenerative MSC effects can be enhanced following exposure to IFN- $\gamma$, 
which induces MSCs to produce high quantities of proangiogeneic VEGF [88]. Additionally, MSC recruitment of alternatively activated macrophages to the site can serve as an additional source of VEGF [87]. MSC interactions with macrophages can change macrophage proinflammatory activity into anti-inflammatory via release of PGE2 from MSCs, which, in turn, binds to EP2 and EP4 receptors on macrophages to induce high-level IL-10 production [87]. MSC interactions with macrophages can also increase the capacity of macrophages to phagocytose apoptotic cells [77,89]. Removal of apoptotic cells and clearance of debris at the lesion site in experimental models of MS appears to correlate with the recruitment of stem cell populations as well as the induction of neurogenesis [90]. MSCs enhance phagocytic activities of the microglia in rodent models of Alzheimer's disease and cerebral ischemia; therefore, enhanced phagocytosis may be beneficial in neural regeneration and repair [91,92]. The ability of IFN- $\gamma$-exposed MSCs to augment these regenerative properties has been observed in a rodent model of wound healing in which wound healing is profoundly delayed. Wounds of aged mice or young mice were treated with naive MSCs or IFN- $\gamma$ activated MSCs, and tensile wound strength was measured as a reflection of regeneration [LEE S, Szliagyi E, Chen L et al. Activated mesenchymal stem CELLS INCREASE WOUND TENSILE STRENGTH IN AGED MOUSE model via macrophages (2012), Submitted]. In young animals, IFN- $\gamma$-activated MSCs were equivalent to five-times the number of naive MSCs in promoting tensile strength. For aged mice, IFN- $\gamma$ activated MSCs restored their tensile strength to that of young animals, and did so through a macrophage-dependent mechanism. In a recent report on the reduced expression of VEGF-A in the cells of the cerebrospinal fluid of MS patients, irrespective of disease course, patients in the secondary progressive phase of MS also manifested reduced $V E G F-A$ mRNA expression in peripheral blood monocytes [93]. One could speculate that deficiencies in proregenerative signals both locally as well as through circulating monocytes may contribute to MS progression and that ex vivo IFN- $\gamma$ priming of MSCs may be more effective in overcoming these specific obstacles than naive MSCs.

\section{MS as a therapeutic target for MSC therapy}

MS pathogenesis is multifactorial and results in multifocal CNS lesions with perivenular inflammation, demyelination, axonal transection, neuronal degeneration and gliosis in both white and gray matter [1]. Inflammatory mechanisms (as reviewed above) predominate in the early stages of the disease, reflected most directly in relapses and MRI-detected lesion activity; however, gradual worsening in progressive MS is currently thought to be due to neurodegeneration. Also, although intrinsic repair processes exist in MS, they do not sufficiently compensate for ongoing damage in most patients. Currently approved MS treatments primarily target CNS inflammation. Treatment strategies to prevent tissue damage or augment repair, including both remyelination and axonal regeneration, are greatly needed. The immunomodulatory, tissue protective and repair-promoting properties of MSCs make them an attractive candidate therapy [12].

\section{Therapeutic MSC transplantation}

To date, the largest studies of therapeutic MSC transplantation have been in hematologic malignancies, breast cancer, GvHD, and acute and chronic ischemic heart disease [94]. There have also been reports of individual patients or small case series with a wide range of other conditions, including neurologic disorders such as acute stroke, spinal cord injury, cerebral trauma, Parkinson's disease, multisystem atrophy and amyotrophic lateral sclerosis. The published experience in MS is modest (TABLE 2). Recently, Connick et al. published the results of the only formal Phase I/IIa study to date, in which ten patients with secondary progressive MS and evidence of involvement of the anterior afferent visual pathways were treated with a single intravenous infusion of autologous culture-expanded, BM-derived MSCs (1.1-2.0 million cells $/ \mathrm{kg}$ of bodyweight of bodyweight) [95]. Patients were followed in this open-label study for up to 20 months pretreatment and 10 months posttreatment. No severe or serious adverse events were reported. Preliminary efficacy analyses demonstrated benefit on some measures of structure and function of the visual pathways.

\section{Autologous versus allogeneic MSCs for therapeutic transplantation}

One area of uncertainty is whether transplantation of autologous or allogeneic MSCs is preferable in disorders such as MS. This uncertainty is based on the theoretical concern that, owing to the underlying disease or its treatment, autologous MSCs from MS patients could have 'defective' immunomodulatory, tissueprotective or -reparative properties. Allogeneic 


\section{Table 2. Published studies of mesenchymal stromal cell transplantation in multiple sclerosis.}

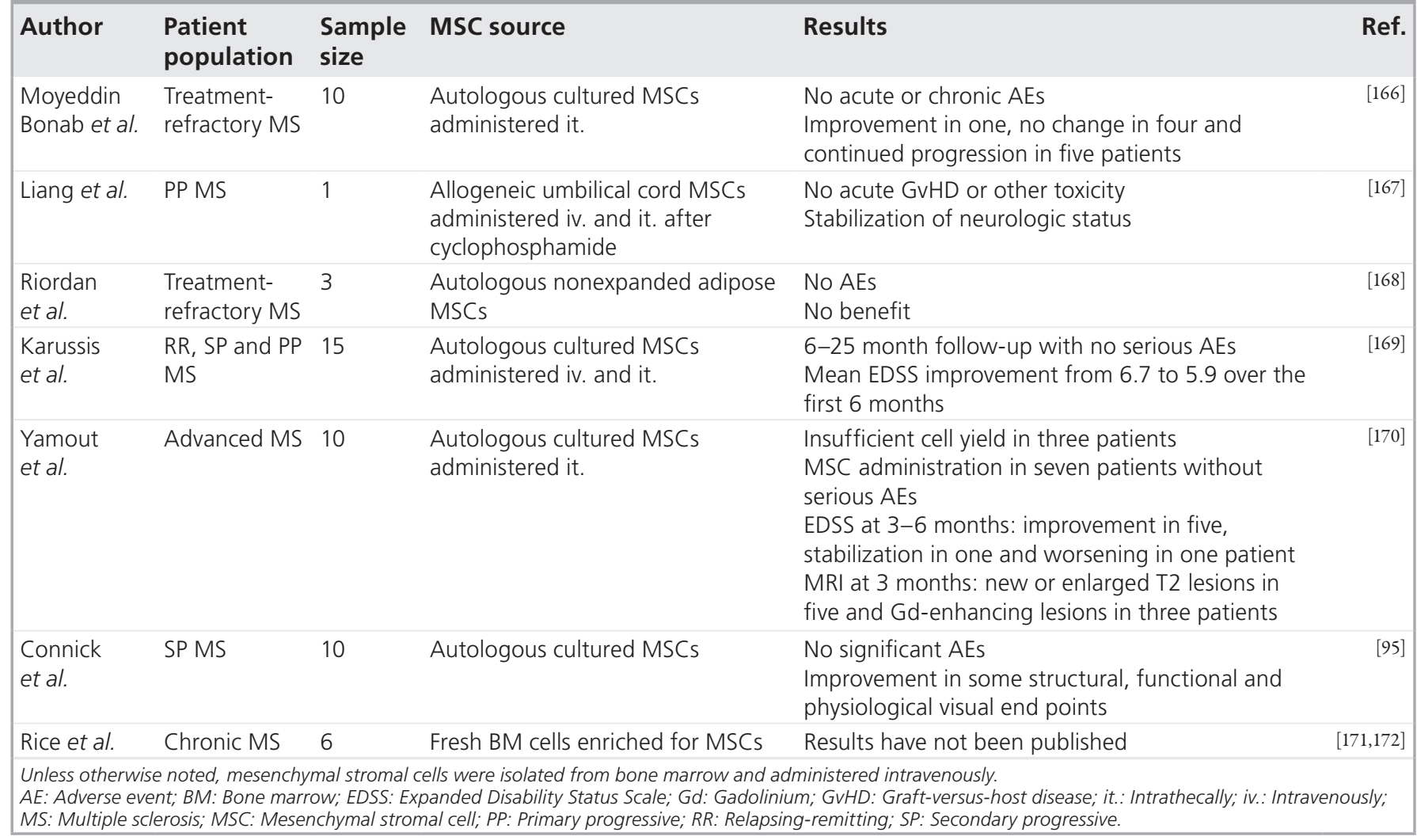

MSC transplantation appears feasible as MSCs are minimally immunogenic. In vitro, human MSCs do not stimulate proliferation or IFN- $\gamma$ production by allogeneic T cells [96-99]. They are not lysed and do not induce production of IFN- $\gamma$ or TNF- $\alpha$ by allogeneic cytotoxic T cells $[37,100]$. In vivo, allogeneic and xenogeneic MSCs are not rejected in mice [101], and numerous studies demonstrate that allogeneic MSCs are not rejected in humans [102-105]. This property allows for use of universal donor, allogeneic culture-expanded MSCs, an approach taken by several companies commercializing MSC therapy. The use of MSCs as an 'off-the-shelf' reagent improves convenience and allows purified MSCs to be used to treat acute conditions, for example acute myocardial infarction or MS relapse. Furthermore, this approach is clearly necessary for the use of MSCs as a replacement therapy in genetic disorders such as osteogenesis imperfecta, Hunter syndrome, metachromatic leukodystrophy and Hurler syndrome [106-109].

However, no published data directly support the hypothesis that MSCs derived from MS patients have a decreased therapeutic potential. Also, although allogeneic transplantation is feasible, it raises a number of practical concerns. First, 'certification' of the donor to rule out infection and cancer must be more comprehensive.
Second, regulatory hurdles would be expected to be more difficult. Finally, chronic disorders such as MS will probably require repeated MSC transplants. Despite MSCs being immunologically privileged, repeated MSC administration could lead to sensitization and increased risk of rejection.

\section{Factors affecting the characteristics of isolated MSCs}

Aspects of cell harvest, culture, cryopreservation and thaw as well as administration have effects on MSC function [110,111]. However, clinical disease states affect MSC function differently. For example, MSCs from patients with aplastic anemia [112], advanced osteoarthritis [113] and connective tissue diseases [114,115] had altered proliferation and/or function. By contrast, MSCs from patients with systemic lupus erythematosus, rheumatoid arthritis, systemic sclerosis, Sjogrens syndrome, polymyalgia rheumatica or diabetes had a similar surface phenotype, plaque-forming ability, differentiation capacity, ability to support hematopoiesis and immunomodulatory properties as control (healthy donor) MSCs, suggesting that these diseases and their associated immunosuppressant therapies did not adversely affect the MSC functions studied $[116,117]$. Likewise, BM 
stromal cells from 15 MS patients supported hematopoiesis normally, and no effect of recent IFN- $\beta$ treatment was apparent [18]. MSCs from five MS patients had similar proliferation, differentiation potential and cell surface antigen expression as five healthy donors [119]. MSCs isolated from ten MS patients had similar proliferation, differentiation capacity, TLR expression, immunomodulatory actions, ability to inhibit dendritic cell differentiation and activation, but significantly greater lipopolysaccharidestimulated IP10 production, compared with six healthy controls [120]. Given these results, it remains uncertain whether MSCs from MS patients have truly altered immunomodulatory and/or repair capacity. To address this need, current trials will further define MSC function in MS patients.

\section{- Potential safety issues with MSC transplantation}

In general, therapeutic MSC transplantation, including with allogeneic MSCs, has been well tolerated. Up to $10 \times 10^{6} \mathrm{cells} / \mathrm{kg}$ of bodyweight can be infused safely [108]. Neither acute nor long-term clinically significant adverse events attributable to MSCs have been reported. Nevertheless, several potential adverse effects will require close attention in future trials (Box 1).

\section{Infusion-related toxicity}

Most clinical trials have reported no infusionrelated adverse events. One patient developed encephalopathy, stroke and myocardial infarction related to dimethyl sulfoxide, a component of the freezing medium [121]. Antifetal bovine serum antibodies are common, but are not usually clinically significant [122]. One study reported a participant who had a 150-fold increase in antifetal bovine serum antibodies and developed an urticarial rash following a second allogeneic MSC infusion [123]. Because MSCs are relatively large cells $(20-60 \mu \mathrm{m})$ [124] and cell clumping is possible, pulmonary embolism is a potential concern. No study has reported respiratory symptoms, decreased oxygen saturation or changes in chest $\mathrm{x}$-rays. Adherence to established procedures for thawing and infusing cells should minimize the potential for these adverse events.

\section{Infection}

MSCs might become contaminated during harvest, manipulation or infusion. One series reported a patient with GvHD who developed central line infection and cellulitis [125], a not uncommon experience in critically ill patients. Aseptic techniques during BM aspiration and infusion, strict culture protocols and stringent microbiologic screening are needed to minimize the risk of infusion-related infection.

Furthermore, the immunologic actions of MSCs potentially could increase the risk of infection. MSCs inhibit lymphocyte proliferative responses to herpes viruses, and Candida albicans mannan and Staphylococcus aureus protein A [126]. MSC effects on virus-specific T-cell responses appear to be lower than on other immune responses, for example to alloantigens [127]. Infections have occurred relatively frequently in some series. However, all of the reported cases involved already immunocompromised patients with cancer or GvHD following hematopoietic stem cell transplantation $[102,128,129]$. Specifically, there have been no reports of opportunistic infection attributable

\section{Box 1. Considerations for mesenchymal stromal cell transplantation in multiple} sclerosis.

- MSC transplantation needs to be combined with anti-inflammatory disease therapy, the effects of which on MSC biology have not been studied

- The route of administration needs to account for the multifocality of lesions

- MS is a chronic disease, repeated transplantation may be necessary

- The MS disease process evolves over time; the appropriate time window for transplantation needs to be identified

- Functional restoration requires appropriate terminal differentiation and functional integration of neural cells

- The MS immune system, CNS or therapies may create an inhospitable environment for stem cells

- MSCs from MS patients may be 'defective'

- MS patients may be at increased risk for allergic phenomena

- Because of potential proinflammatory effects of MSCs, transplantation could lead to paradoxical disease activation, as has been observed with some other therapies

MS: Multiple sclerosis; MSC: Mesenchymal stromal cell. 
to MSC transplantations and emerging literature suggests that MSCs may contribute to antimicrobial host responses (as reviewed in Auletta et al. [66]).

\section{Cancer}

The potential for malignant transformation would not be unexpected, given some of the biologic similarities between stem cells and cancer cells. MSCs in adults may become tumorigenic $[130,131]$ and have been implicated in several human or experimental tumors, including childhood leukemia [132], gastric epithelial cancers [133] and osteogenic sarcomas [134]. In a study by Tolar et al., the high frequency of osteogenic sarcomas in the murine lung after MSC transplantation appeared to be related to the propensity of murine cells to develop frequent karyotypic abnormalities, even in short-term culture [134]. Karytotypic abnormalities have not been seen in some studies of human MSCs [135], but have been reported in others [136-138], predominantly with prolonged culture. Thus, an important factor appears to be continuing cultures following senescent crisis $[139,140]$.

Several studies have demonstrated homing of MSCs to primary and metastatic cancers, wherein they may form tumor stroma [141]. In addition, trophic or immunosuppressive effects of MSCs could create a permissive environment for cancer development. For example, MSC-derived adipocytes reduced apoptosis of acute promyelocytic leukemia cells in culture [142]. Human MSCs mixed with human breast cancer cells injected as a subcutaneous xenograft in mice led to a marked increase in metastatic potential [143]. MSCs prolonged the survival of B16 melanoma tumor cells when coinjected subcutaneously in mice [101]. Finally, in a randomized trial in hematologic malignancies of sibling MHC-matched hematopoietic stem cells with or without MSCs, there was decreased GvHD in MSC recipients (11.1 vs $53.3 \%$ ) but increased leukemia relapse: six out of ten $(60.0 \%)$ versus three out of 15 patients (20.0\%) [129]. Despite these theoretical concerns, there are no reports of de novo tumor formation complicating MSC transplantation in humans, either directly derived from transplanted MSCs or from indirect permissive effects of MSCs on other cell types. Nonetheless, in planned clinical trials, MSCs should be passaged the minimum times needed to obtain a sufficient cell yield to lessen potential for cytogenetic abnormalities, and an additional consideration should be given to potentially exclude participants with a concomitant cancer history.

\section{Ectopic tissue formation}

MSCs can differentiate into a number of mesodermal tissues and, possibly, cells derived from other germ layers. Ectopic calcification and/or ossification were observed with direct MSC injection into infarcted mouse myocardium [136]. However, ectopic tissue formation has not been reported in human studies and has specifically been evaluated for and not found in seven patients with a MSC-hematopoietic stem cell cotransplantation (follow-up of more than 3 years and autopsy in one participant) [144].

\section{Autoimmunity}

There have been no reports of autoimmune phenomena with MSC transplantation. However, so far, its use in immune-mediated disorders including MS has been extremely limited. Other treatments in MS have produced unanticipated autoimmune phenomena, such as thyroid disease, immune thrombocytopenia purpura and antiglomerular basement membrane disease with alemtuzumab [145], or increased MS disease activity with TNF- $\alpha$ blockers [4]. Because MSCs have both anti-and pro-inflammatory immune effects, as discussed above, monitoring for systemic autoimmune phenomena and paradoxical disease activation should be a focus of future studies of MSC transplantation in MS.

\section{Homing}

The concept of using MSCs for regenerative therapy has been enhanced by the observation that these cells can traffic, home and engraft long term in various target tissues [146]. Following intravenous administration, MSCs appear most numerously in the lungs, but emerging evidence shows that these cells will reach injured or inflamed tissues including the brain. Mechanisms by which MSCs can be recruited to cross endothelial cell layers and infiltrate into tissues are still being defined, but probably involve ligand-receptor interactions $[147,148]$.

\section{Planned study of MSC transplantation for MS}

Several groups have initiated formal studies of MSC transplantation in MS. Our group is carrying out a Phase I trial that will enroll 24 men and women 18-55 years of age with active relapsing forms of MS, an Expanded Disability Status Scale of 3.0-6.5, documented involvement of the anterior afferent visual system and brain MRI demonstrating T2-hyperintense lesions and satisfying diagnostic MS criteria [149,150,201]. Participants will be followed for 2 months pretreatment and 
6 months after intravenous infusion of autologous, culture-expanded, BM-derived MSCs $\left(1-2 \times 10^{6} / \mathrm{kg}\right)$, meeting strict release criteria for sterility, viability and purity. In addition to intensive general safety monitoring, clinical immunology safety assessments will include serologic studies (thyroid stimulating hormone, antithyroglobulin antibodies, antimicrosomal antibodies, sedimentation rate, CRP, antinuclear antibodies, SSA antibodies, SSB antibodies and rheumatoid factor), quantitative immunoglobulin levels and lymphocyte subsets measured by flow cytometry. Efficacy assessments will include participant global impression of health status, relapse rate, neurologic and visual impairment (the Expanded Disability Status Scale, the Multiple Sclerosis Functional Composite, visual acuity testing and Sloan low-contrast letter acuity testing), brain MRI (T2-hyperintense, T1-hypointense, and gadolinium-enhancing lesions, whole-brain and gray matter atrophy, whole-brain magnetization transfer imaging and diffusion tensor imaging), visual evoked potentials (P100 latency) and optical coherence tomography (overall mean and quadrantic peripapillary retinal nerve fiber layer thickness, foveal thickness, macular volume and segmented ganglion cell layer thickness).

Ancillary mechanistic immunologic studies will examine the in vivo effects of autologous MSC transplantation on MS relevant T- and B-cell immune responses at several time points before and after MSC transplantation. The immunologic effects of MSC transplantation will be correlated with clinical and imaging measures of MS disease activity/severity, as well as potential adverse effects. Finally, exploratory in vitro studies will evaluate molecular mechanisms of MSC-induced immunomodulation and predict the in vivo effects of MSC transplantation.

Finally, a consensus meeting of investigators with expertise in MSC biology, MS immunology and MS clinical trials was held in Paris, France in March 2009 to review the laboratory studies of MSCs, clinical experience with MSC transplantation and the rationale and the preliminary experience in MS. The goal was to develop a consensus protocol for future Phase II clinical trials of MSC transplantation in MS, so groups develop formal studies to evaluate MSCs in MS in which the core elements of the protocols will be sufficiently consistent to allow 'pooling' of data [13].

\section{MSC therapy: general considerations for its clinical application}

The complex cellular interactions discussed herein position MS as one of many diseases for the therapeutic application of MSCs in ameliorating disease course. Clinical applications of MSCs originally focused on engraftment [151], given that MSCs are a normal BM constituent [152]. Furthermore, many investigators demonstrated that both cytokines and hematopoietic growth factors could be induced by MSCs, as well as constitutively secreted by MSCs, into media [74]. Preclinical animal studies corroborated the hematopoietic-stimulating potential of these cells. The first in-human MSC clinical trial focused on showing the safety and feasibility of ex vivo expansion and reinfusion [153]. A logical next step was assessing in humans if a stromal cell boost could accelerate engraftment in the setting of high-dose myeloablative therapy with autologous peripheral blood progenitor cell transplantation, as noted in breast cancer patients [154].

Given the success of these initial clinical results, Horwitz and colleagues pursued seminal MSC transplantation studies in children with osteogenesis imperfecta [123]. These investigations focused on exploiting the mesenchymal origin of osteoblasts to increase bone mineralization in osteogenesis imperfecta patients. Bone fracture rates were decreased and overall growth patterns were enhanced in MSC-treated patients; however, engraftment rates of the donor-derived osteoblasts were surprisingly low (1.5-2.0\%). Another first in-human study using allogeneic MSCs provided insights leading to the refocus of MSCs as an immunosuppressive therapy. Lazarus and colleagues cotransplanted ex vivoexpanded MSCs obtained from histocompatible sibling donors as an adjunct therapy for patients undergoing myeloablative matched related donor allogeneic hematopoietic stem cell transplantation [153]. Although engraftment did not appear to be enhanced, findings suggested that adjuvant administration of MSCs contributed to an immunosuppressive benefit, as less GvHD was observed compared with historic data, opening the door for exploring the use of MSCs as immunosuppressive therapy in the context of GvHD.

Following those original studies, a shift in the desired clinical benefits associated with MSC therapy has occurred. One focus has been redirecting the cellular transport of packaged soluble mediators, given the potential of MSCs to elaborate a vast array of cytokines and chemokines. Another focus has been to generate a more universal MSC clinical product, rather than a directed, donor-derived, patient-specific product. Several commercial cellular products have emerged as target applications for immunosuppression and for regenerative medicine in such 
diverse clinical scenarios as acute and chronic GvHD, acute myocardial infarction, critical limb ischemia, osteoarthritis, traumatic spine injury, acute lung injury, inflammatory bowel disease, diabetes mellitus and MS. Universally, safety has been demonstrated. Additionally, in nearly all Phase I and II studies, a maximum tolerated dose has not been demonstrated. Given the high production cost of an expanded MSC product, the focus has shifted towards identifying what may be a more relevant end point, such as the maximum deliverable dose or the minimally effective biologic dose. Unfortunately, these studies have not provided a better understanding of biodistribution or clearance of the infused or injected MSC. In addition, the failure to develop reliable biomarkers and in vivo cell tracking methods for assessing therapeutic efficacy have significantly hampered the scientific community's ability to define MSC as a therapeutic agent.

If MSC therapeutic intervention for MS is to evolve further, then this latter point is worthy of additional comment. Many of the current academic and industrial efforts are focused on defining MSCs as a therapeutic agent or 'drug.' It is important to understand the pharmacodynamics of the drug and the impact of the body on the drug (pharmacokinetics), as well as develop the means to track in vivo drug delivery. Finally, one must address the issue of whether there are physiologic barriers impeding generalized drug distribution. Classical pharmacologic analysis, as well as emerging techniques in systems biology focused at analyzing static and dynamic relationships between drugs and tissues across time and space can be utilized in this regard. However, the major classical impact of the drug is a molecular rather than cellular event; receptor-ligand binding leading to agonist or antagonist signaling, interactions with carrier or structural proteins, enzymatic interactions, ion channel blockade or direct cytotoxicity; these examples are all molecular actions that can be quantified with appropriate tools. It is critical to recognize that none of these functions have been delineated and quantified for cellular products. On the contrary, standard ELISA assays and now more advanced proteomics are identifying a vast array of molecules with multiple functions that are generated by the MSCs in vitro, including growth factors, immunomodulatory soluble factors and matrix components. Emerging technologies have the potential to quantify these parameters at nanogram and picogram levels, recognizing that the MSCs are not drugs, but rather drug-delivery systems.
If the regenerative medicine community is to continue to exploit MSCs for therapeutic purposes, multiple questions remain. What is the optimal time of application? What is the minimum number of cells required to achieve a therapeutic response? Should MSC populations be pretreated ex vivo or activated post-treatment in vivo? What is the preferred route of delivery? Can single applications suffice or must applications be repeated? Is there a need for simultaneous immune suppression? These answers must be generated, recognizing that the available healthcare funding to support these efforts are diminishing. Such approaches require close scrutiny balancing the cost of production and optimization of the MSC effect.

It is naive to think that an off-the-shelf product will have been optimized for universal application for such a vast array of diverse disease entities. For example, the MS patient obviously differs greatly from a patient who has sustained a recent acute myocardial infarction. For MSCs to continue to emerge as an effective therapeutic tool, in the near future we must recognize how to optimize the development of cost-effective therapeutics in this current financial climate. Manipulations of MSCs will probably lead to more optimal therapeutic outcomes. However, therapeutic success will need to be validated, not just in clinical trials, but under the critical scrutiny of evidence-based analyses and be affordable within the constraints of a financially challenged healthcare delivery system.

\section{Conclusion}

The chronic inflammatory, neurodegenerative disease aspects of MS are complex. In this regard, MSC therapy has the potential to target multiple levels of MS pathology, including immunomodulation and neuronal cell repair and regeneration. However, the promise of MSC therapy must be balanced by the need to further define MS pathology as well as in vivo effects of MSCs, which are both critically needed to ensure the translational success of this cellular therapy as a viable treatment and even cure for MS.

\section{Future perspective}

Clinical experience using MSC therapies over the last decade has established the safety profile of these products, so the key restriction of their clinical use remains generation of significant proof of mechanism in Phase II clinical trials. Capital investment from industry and healthcare sectors is critical to undergo larger registration 
trials, but is dependent upon the demonstration of accurate and reproducible clinical results. As a result, advancement of MSC-based therapies in autoimmunity is currently at a pivotal point, with transition from proof-of-concept observations to evaluation of MSC transplantation as effective disease treatment. Despite defined mechanistic therapeutic pathways in MS, major gaps in understanding MS pathophysiology remain, as well as in MSC biology and function in the context of neuronal disease, which will ultimately limit the success in using MSC transplantation to cure MS. Furthermore, a dearth in understanding of cellular therapy pharmacologic principles such as pharmacokinetics/pharmacodynamics will also hinder dose optimization in ensuring a durable clinical response. Therefore, integrating crosstalk between the therapeutic cell product and the disease microenvironment with defining clinical end points and biomarker analysis will be essential. Such investigations will increase the future likelihood that the disease mechanism and treatment effect are reconciled.

Whether cell therapeutic approaches can compete in efficacy and cost with drugs and biologics currently in the MS treatment pipeline remains to be determined. The dynamic and multimodal response pathways seemingly utilized by MSC therapy appear advantageous in inducing longterm autoimmune suppression and neuronal repair compared with single-modality drug or biologic approaches. However, such an advantage in potential effect is counterbalanced by the high cost of production associated with cell therapeutics, which is heightened by an allogeneic versus autologous approach.

The use of allogeneic MSC therapy risks immune sensitization and clearance of the therapeutic cell product, and measuring such risk should be the focus of future mid-stage clinical studies. In principle, an autologous approach minimizes risk in allosensitization, but unanswered questions remain with regards potency and variability of MSC products derived from patients with disease. Improved bioassays for MSC characterization and potency responses should work to resolve this issue.

Based upon the competition and evolution of new bioprocessing technology, universal donor MSC therapies may evolve into a low-margin, high-volume commodity for both pharmaceutical and healthcare industries. By contrast, the autologous production model will benefit from bioprocessing technology investment driven by personalized medicine concepts linked to induced pluripotent stem cell and embryonic stem cell therapies in the regenerative medicine space. Regardless of self-versus-nonself MSC source, thoughtful and methodical advancement in clinical proof of mechanism will be essential

Executive summary

\section{Animal models of multiple sclerosis: advancing understanding of mesenchymal stromal cell effects}

- Ongoing studies will provide mechanistic insights into the roles that mesenchymal stromal cells (MSCs) have in modulating the immune response in models of inflammatory-mediated demyelination.

- The molecular basis of MSC influence on neural cell genesis, survival and differentiation will be defined.

- The properties of MSCS that influence myelin repair in the adult vertebrate CNS can be characterized by animal models of multiple sclerosis (MS).

\section{New experimental directions for MSC therapy: implications of exploiting Toll-like receptors}

- Toll-like receptors (TLRs) critically link pathogen- and damage-induced inflammatory pathways, as well as innate and adaptive immune responses.

- The proinflammatory microenvironment associated with MS contains TLR ligands and TLR-inducible soluble cytokines and chemokines, which can potentially modulate MSC immune function and regenerative capacity.

- Targeting TLRs and their signaling cascades can potentially influence MS pathogenesis through effects on neuronal cells, immune cells and MSCs.

Harnessing MSC therapeutic potential through inflammation: role of IFN- $\gamma$ activation

- IFN- $\gamma$ modulates the immune function and regenerative capacity of MSCs.

- Prestimulation with IFN- $\gamma$ offers the potential to direct MSC function and to enhance its efficacy.

MS as a therapeutic target for MSC therapy

- Ongoing studies will assess the safety and tolerability of MSC transplantation in MS and provide a preliminary indication of whether MSCs have beneficial anti-inflammatory or repair-promoting effects.

\section{MSC therapy: general considerations for clinical application}

- Current clinical indications of MSC therapy exploit the immunomodulatory and regenerative properties inherent in these cells.

- Successful demonstration of efficacy of MSC therapy is predicated upon enhancing the understanding for in vivo administration (dose, route and frequency), distribution and interaction with other cells and tissues in the body. 
for the successful application of MSC therapy for MS. Ultimately, the most effective therapeutic approach will drive technology investment to bring MSC-based treatment of autoimmunity towards standard of care.

\section{Acknowledgements}

The topics covered in this presentation were presented in part at the International Stem Cell Therapy (ISCT) North America Cell Therapy Symposium (September 2011) in Charlottesville, VA, USA.

Financial \& competing interests disclosure JJ Auletta, RJ Deans, RH Miller, HM Lazarus and $J A$ Cohen wish to acknowledge the National Center for Regenerative Medicine at Case Western Reserve
University for its financial research support. JJ Auletta and $A M$ Bartholomew have received funding from NIH/NIAID AI57801 and AI089556 grants, respectively. JA Cohen has received funding from the DOD PRMRP grant W81XWH-10-1-0271 and NIH/NINDS NS074787 grant. RJ Deans is a paid employee and share option holder of Athersys, Inc. JA Cohen has received compensation for serving as a consultant or speaker for Biogen Idec, Novartis, Teva and Vaccinex. The authors have no other relevant affiliations or financial involvement with any organization or entity with a financial interest in or financial conflict with the subject matter or materials discussed in the manuscript apart from those disclosed.

No writing assistance was utilized in the production of this manuscript.

\section{References}

Papers of special note have been highlighted as:

- of interest

" of considerable interest

1 Frohman EM, Racke MK, Raine CS. Multiple sclerosis - the plaque and its pathogenesis. N. Engl. J. Med. 354(9), 942-955 (2006).

2 Mix E, Meyer-Rienecker H, Hartung HP, Zettl UK. Animal models of multiple sclerosis - potentials and limitations. Prog. Neurobiol. 92(3), 386-404 (2010).

3 Carrithers MD. Current immunotherapy of multiple sclerosis and future challenges: relevance of immune-mediated repair. Curr. Pharm. Biotechnol. (2012) (Epub ahead of print).

4 The Lenercept Multiple Sclerosis Study Group; the University of British Columbia MS/MRI Analysis Group. TNF neutralization in MS. Results of a randomized, placebocontrolled multicenter study. Neurology 53 , 457-465 (1999).

5 Pittenger MF, Mackay AM, Beck SC et al. Multilineage potential of adult human mesenchymal stem cells. Science 284(5411), 143-147 (1999).

- Landmark publication defining human mesenchymal stromal cell (MSC) differentiation potential.

6 Rosada C, Justesen J, Melsvik D, Ebbesen P, Kassem M. The human umbilical cord blood: a potential source for osteoblast progenitor cells. Calcif. Tissue Int. 72(2), 135-142 (2003).

7 Igura K, Zhang X, Takahashi K, Mitsuru A, Yamaguchi S, Takashi TA. Isolation and characterization of mesenchymal progenitor cells from chorionic villi of human placenta. Cytotherapy 6(6), 543-553 (2004).

8 Siepe M, Thomsen AR, Duerkopp N et al. Human neonatal thymus-derived mesenchymal stromal cells: characterization, differentiation, and immunomodulatory properties. Tissue Eng. Part A 15(7), 1787-1796 (2009).

9 Zhang Q, Shi S, Liu Y, Uyanne J, Shi Y, Le AD. Mesenchymal stem cells derived from human gingiva are capable of immunomodulatory functions and ameliorate inflammation-related tissue destruction in experimental colitis. J. Immunol. 183(12), 7787-7798 (2009).

10 Dominici M, Le Blanc K, Mueller I et al. Minimal criteria for defining multipotent mesenchymal stromal cells. The International Society for Cellular Therapy position statement. Cytotherapy 8(4), 315-317 (2006).

- International criteria for defining MSCs.

11 Auletta JJ, Cooke KR, Solchaga LA, Deans RJ, van't Hof W. Regenerative stromal cell therapy in allogeneic hematopoietic stem cell transplantation: current impact and future directions. Biol. Blood Marrow Transplant. 16(7), 891-906 (2010).

12 Siatskas C, Payne NL, Short MA, Bernard CC. A consensus statement addressing mesenchymal stem cell transplantation for multiple sclerosis: it's time! Stem Cell Rev. 6(4), 500-506 (2010).

13 Freedman MS, Bar-Or A, Atkins HL et al. The therapeutic potential of mesenchymal stem cell transplantation as a treatment for multiple sclerosis: consensus report of the International MSCT Study Group. Mult. Scler. 16(4), 503-510 (2010).

14 Maltman DJ, Hardy SA, Przyborski SA. Role of mesenchymal stem cells in neurogenesis and nervous system repair. Neurochem. Int. 59(3), 347-356 (2011).

15 Opitz CA, Litzenburger UM, Lutz C et al. Toll-like receptor engagement enhances the immunosuppressive properties of human bone marrow-derived mesenchymal stem cells by inducing indoleamine-2,3dioxygenase-1 via interferon-beta and protein kinase R. Stem Cells 27(4), 909-919 (2009).

16 Ryan JM, Barry F, Murphy JM, Mahon BP. Interferon-gamma does not break, but promotes the immunosuppressive capacity of adult human mesenchymal stem cells. Clin. Exp. Immunol. 149 (2), 353-363 (2007).

17 Gambuzza M, Licata N, Palella E et al. Targeting Toll-like receptors: emerging therapeutics for multiple sclerosis management. J. Neuroimmunol. 239(1-2), 1-12 (2011).

- Excellent review on the role of Toll-like receptors in multiple sclerosis.

18 Codarri L, Fontana A, Becher B. Cytokine networks in multiple sclerosis: lost in translation. Curr. Opin Neurol. 23(3), 205-211 (2010).

19 Krishnamoorthy G, Wekerle H. EAE: an immunologist's magic eye. Eur. J. Immunol. 39 (8), 2031-2035 (2009).

20 Marta M. Toll-like receptors in multiple sclerosis mouse experimental models. Ann. NY Acad. Sci. 1173, 458-462 (2009).

21 Steinman L. Multiple sclerosis: a two-stage disease. Nat. Immunol. 2(9), 762-764 (2001).

22 Guo X, Harada C, Namekata K et al. Regulation of the severity of neuroinflammation and demyelination by TLR-ASK1-p38 pathway. EMBO Mol. Med. 2(12), 504-515 (2010).

23 Franklin RJ. Why does remyelination fail in multiple sclerosis? Nat. Rev. Neurosci. 3(9), 705-714 (2002).

24 Uccelli A, Pistoia V, Moretta L. Mesenchymal stem cells: a new strategy for immunosuppression? Trends Immunol. 28(5), 219-226 (2007). 
25 Bai L, Lennon DP, Eaton V et al. Human bone marrow-derived mesenchymal stem cells induce Th2-polarized immune response and promote endogenous repair in animal models of multiple sclerosis. Glia 57(11), 1192-1203 (2009).

- Animal model defining mechanisms underlying human MSCs improvement in murine experimental autoimmune encephalitis.

26 Zhang J, Li Y, Chen J. Human bone marrow stromal cell treatment improves neruological functional recovery in EAE mice. Exp. Neurology 195, 16-26 (2005).

27 Gerdoni E, Gallo B, Casazza S et al. Mesenchymal stem cells effectively modulate pathogenic immune response in experimental autoimmune encephalomyelitis. Ann. Neurol. 61(3), 219-227 (2007).

28 Zappia E, Casazza S, Pedemonte E. Mesenchymal stem cells ameliorate experimental autoimmune encephalomyelitis inducing T cell anergy. Blood 106(5), 1755-1761 (2005).

29 Miller RH, Bai L. Cellular approaches for stimulating CNS remyelination. Regen. Med. 2(5), 817-829 (2007).

30 Romieu-Mourez R, Coutu DL, Galipeau J. The immune plasticity of mesenchymal stromal cells from mice and men: concordances and discrepancies. Front. Biosci. (Elite Ed.) 4, 824-837 (2012).

31 Nauta AJ, Fibbe WE. Immunomodulatory properties of mesenchymal stromal cells. Blood 110 (10), 3499-3506 (2007).

32 Zepp J, Wu L, Li X. IL-17 receptor signaling and $\mathrm{T}$ helper 17-mediated autoimmune demyelinating disease. Trends Immunol. 32(5), 232-239 (2011).

33 Gage FH. Mammalian neural stem cells. Science 287, 1433-1438 (2000).

34 Reynolds BA, Weiss S. Generation of neurons and astrocytes from isolated cells of the adult mammalian central nervous system. Science 255, 1707-1710 (1992).

35 Fuller ML, DeChant AK, Rothstein B et al. Bone morphogenetic proteins promote gliosis in demyelinating spinal cord lesions. Ann. Neurol. 62(3), 288-300 (2007).

36 Munoz JR, Stoutenger BR, Robinson AP, Spees JL, Prockop DJ. Human stem/progenitor cells from bone marrow promote neurogenesis of endogenous neural stem cells in the hippocampus of mice. Proc. Natl Acad. Sci. USA 102(50), 18171-18176 (2005).

37 Rasmusson I, Ringden O, Sundberg B, Le Blanc K. Mesenchymal stem cells inhibit the formation of cytotoxic T lymphocytes, but not activated cytotoxic T lymphocytes or natural killer cells. Transplantation 76(8), 1208-1213 (2003).

38 Oswald J, Boxberger S, Jorgensen B et al. Mesenchymal stem cells can be differentiated into endothelial cells in vitro. Stem Cells 22(3), 377-384 (2004).

39 Jiang Y, Jahagirdar BN, Reinhardt RL et al. Pluripotency of mesenchymal stem cells derived from adult marrow. Nature 418(6893), 41-49 (2002).

40 Rutenberg MS, Hamazaki T, Singh AM, Terada N. Stem cell plasticity, beyond alchemy. Int. J. Hematol. 79(1), 15-21 (2004).

41 Rivera FJ, Couillard-Despres S, Pedre X et al. Mesenchymal stem cells instruct oligodendrogenic fate decision on adult neural stem cells. Stem Cells 24(10), 2209-2219 (2006).

42 Kawai T, Akira S. The role of pattern-recognition receptors in innate immunity: update on Toll-like receptors. Nat. Immunol. 11(5), 373-384 (2010).

43 An H, Xu H, Yu Y et al. Up-regulation of ${ }^{\text {TLR9 }}$ gene expression by LPS in mouse macrophages via activation of NF-kappaB, ERK and p38 MAPK signal pathways. Immunol. Lett. 81(3), 165-169 (2002).

44 De Rycke L, Vandooren B, Kruithof E, De Keyser F, Veys EM, Baeten D. Tumor necrosis factor alpha blockade treatment down-modulates the increased systemic and local expression of Toll-like receptor 2 and Toll-like receptor 4 in spondylarthropathy. Arthritis Rheum. 52(7), 2146-2158 (2005).

45 Sallusto F, Palermo B, Lenig D et al. Distinct patterns and kinetics of chemokine production regulate dendritic cell function. Eur. J. Immunol. 29(5), 1617-1625 (1999).

46 Kawai T, Akira S. Toll-like receptors and their crosstalk with other innate receptors in infection and immunity. Immunity 34(5), 637-650 (2011).

47 Sims GP, Rowe DC, Rietdijk ST, Herbst R, Coyle AJ. HMGB1 and RAGE in inflammation and cancer. Annu. Rev. Immunol. 28, 367-388 (2010).

48 Andersson A, Covacu R, Sunnemark D et al. Pivotal advance: HMGB1 expression in active lesions of human and experimental multiple sclerosis. J. Leukoc. Biol. 84(5), 1248-1255 (2008).

49 Mills KH. TLR-dependent T cell activation in autoimmunity. Nat. Rev. Immunol. 11(12), 807-822 (2011).

50 Gutcher I, Donkor MK, Ma Q, Rudensky AY, Flavell RA, Li MO. Autocrine transforming growth factor-betal promotes in vivo Th17 cell differentiation. Immunity 34(3), 396-408 (2011).

51 Gilgun-Sherki Y, Melamed E, Offen D.

The role of oxidative stress in the pathogenesis of multiple sclerosis: the need for effective antioxidant therapy. J. Neurol. 251(3), 261-268 (2004).

52 Bach JF. The effect of infections on susceptibility to autoimmune and allergic diseases. N. Engl. J. Med. 347(12), 911-920 (2002).

53 Krone B, Grange JM. Multiple sclerosis: are protective immune mechanisms compromised by a complex infectious background? Autoimmune Dis. 2011, 708750 (2010).

54 Carty M, Bowie AG. Evaluating the role of Toll-like receptors in diseases of the central nervous system. Biochem. Pharmacol. 81(7), 825-837 (2011).

55 Touil T, Fitzgerald D, Zhang GX, Rostami A, Gran B. Cutting edge: TLR3 stimulation suppresses experimental autoimmune encephalomyelitis by inducing endogenous IFN-beta. J. Immunol. 177(11), 7505-7509 (2006).

56 Darlington PJ, Boivin MN, Renoux C et al. Reciprocal Th1 and Th17 regulation by mesenchymal stem cells: implication for multiple sclerosis. Ann. Neurol. 68(4), 540-545 (2010).

57 Griffin MD, Ritter T, Mahon BP. Immunological aspects of allogeneic mesenchymal stem cell therapies. Hum. Gene Ther. 21(12), 1641-1655 (2010).

58 Singer NG, Caplan AI. Mesenchymal stem cells: mechanisms of inflammation. Annu. Rev. Pathol. 6, 457-478 (2011).

59 Bassi EJ, de Almeida DC, Moraes-Vieira PM, Camara NO. Exploring the role of soluble factors associated with immune regulatory properties of mesenchymal stem cells. Stem Cell Rev. doi:10.1007/s12015011-9311-1 (2011) (Epub ahead of print).

60 Ghannam S, Pene J, Torcy-Moquet G, Jorgensen C, Yssel H. Mesenchymal stem cells inhibit human Th17 cell differentiation and function and induce a $T$ regulatory cell phenotype. J. Immunol. 185(1), 302-312 (2010).

61 English K, Ryan JM, Tobin L, Murphy MJ, Barry FP, Mahon BP. Cell contact, prostaglandin E(2) and transforming growth factor beta 1 play non-redundant roles in human mesenchymal stem cell induction of $\mathrm{CD} 4{ }^{+} \mathrm{CD} 25^{\text {(high) }}$ forkhead box $\mathrm{P}^{+}$regulatory T cells. Clin. Exp. Immunol. 156(1), 149-160 (2009).

62 Chiesa S, Morbelli S, Morando S et al. Mesenchymal stem cells impair in vivo T-cell priming by dendritic cells. Proc. Natl 
Acad. Sci. USA 108(42), 17384-17389

(2011).

63 Krampera M. Mesenchymal stromal cell 'licensing': a multistep process. Leukemia 25(9), 1408-1414 (2011).

64 Bunnell BA, Betancourt AM, Sullivan DE. New concepts on the immune modulation mediated by mesenchymal stem cells. Stem Cell Res. Ther. 1(5), 34 (2010)

65 DelaRosa O, Lombardo E. Modulation of adult mesenchymal stem cells activity by Toll-like receptors: implications on therapeutic potential. Mediators Inflamm. 2010, 865601 (2010)

66 Auletta JJ, Deans RJ, Bartholomew AM. Emerging roles for multipotent, bone marrow-derived stromal cells in host defense. Blood 119 (8), 1801-1809 (2012).

67 Dazzi F, Krampera M. Mesenchymal stem cells and autoimmune diseases. Best Pract. Res. Clin. Haematol. 24(1), 49-57 (2011).

68 Waterman RS, Tomchuck SL, Henkle SL, Betancourt AM. A new mesenchymal stem cell (MSC) paradigm: polarization into a pro-inflammatory MSC1 or an Immunosuppressive MSC2 phenotype. PLoS ONE 5(4), e10088 (2010).

69 Tomchuck SL, Zwezdaryk KJ, Coffelt SB, Waterman RS, Danka ES, Scandurro AB.

Toll-like receptors on human mesenchymal stem cells drive their migration and immunomodulating responses. Stem Cells 26(1), 99-107 (2008).

70 Jack CS, Arbour N, Manusow J et al. TLR signaling tailors innate immune responses in human microglia and astrocytes. J. Immunol. 175(7), 4320-4330 (2005).

71 Bsibsi M, Persoon-Deen C, Verwer RW, Meeuwsen S, Ravid R, Van Noort JM. Toll-like receptor 3 on adult human astrocytes triggers production of neuroprotective mediators. Glia 53(7), 688-695 (2006).

72 Prehaud C, Megret F, Lafage M, Lafon M. Virus infection switches TLR-3-positive human neurons to become strong producers of beta interferon. J. Virol. 79(20), 12893-12904 (2005).

73 Liu Y, Wang L, Kikuiri T et al. Mesenchymal stem cell-based tissue regeneration is governed by recipient T lymphocytes via IFN-gamma and TNF-alpha. Nat. Med. 17(12), 1594-1601 (2011).

74 Caplan AI, Dennis JE. Mesenchymal stem cells as trophic mediators. J. Cell. Biochem. 98(5), 1076-1084 (2006).

75 Devine SM, Cobbs C, Jennings M, Bartholomew A, Hoffman R. Mesenchymal stem cells distribute to a wide range of tissues following systemic infusion into nonhuman primates. Blood 101(8), 2999-3001 (2003).

- Landmark publication demonstrating MSC biodistribution in vivo.

76 English K, Barry FP, Field-Corbett CP, Mahon BP. IFN-gamma and TNF-alpha differentially regulate immunomodulation by murine mesenchymal stem cells. Immunol. Lett. 110 (2), 91-100 (2007).

77 Kim J, Hematti P. Mesenchymal stem cell-educated macrophages: a novel type of alternatively activated macrophages. Exp. Hematol. 37(12), 1445-1453 (2009).

78 Chen L, Tredget EE, Wu PY, Wu Y. Paracrine factors of mesenchymal stem cells recruit macrophages and endothelial lineage cells and enhance wound healing. PLoS ONE 3(4), e1886 (2008).

79 Nakajima H, Uchida K, Rodriguez Guerrero A et al. Transplantation of mesenchymal stem cells promotes the alternative pathway of macrophage activation and functional recovery after spinal cord injury. J. Neurotrauma doi:10.1089/neu.2011.2109 (2012) (Epub ahead of print).

80 Chan JL, Tang KC, Patel AP et al. Antigen-presenting property of mesenchymal stem cells occurs during a narrow window at low levels of interferon-gamma. Blood 107(12), 4817-4824 (2006).

81 Stagg J. Immune regulation by mesenchymal stem cells: two sides to the coin. Tissue Antigens 69(1), 1-9 (2007).

82 Meisel R, Zibert A, Laryea M, Gobel U, Daubener W, Dilloo D. Human bone marrow stromal cells inhibit allogeneic T-cell responses by indoleamine

2,3-dioxygenase-mediated tryptophan degradation. Blood 103(12), 4619-4621 (2004).

83 Polchert D, Sobinsky J, Douglas G et al. IFN-gamma activation of mesenchymal stem cells for treatment and prevention of graft versus host disease. Eur. J. Immunol. 38(6), 1745-1755 (2008).

84 Schena F, Gambini C, Gregorio A et al. Interferon-gamma-dependent inhibition of $\mathrm{B}$ cell activation by bone marrow-derived mesenchymal stem cells in a murine model of systemic lupus erythematosus. Arthritis Rheum. 62(9), 2776-2786 (2010).

85 Schurgers E, Kelchtermans H, Mitera T, Geboes L, Matthys P. Discrepancy between the in vitro and in vivo effects of murine mesenchymal stem cells on T-cell proliferation and collagen-induced arthritis. Arthritis Res. Ther. 12(1), R31 (2010).

86 Wu Y, Chen L, Scott PG, Tredget EE. Mesenchymal stem cells enhance wound healing through differentiation and angiogenesis. Stem Cells 25(10), 2648-2659 (2007).

87 Nemeth K, Leelahavanichkul A, Yuen PS et al. Bone marrow stromal cells attenuate sepsis via prostaglandin $\mathrm{E}(2)$-dependent reprogramming of host macrophages to increase their interleukin-10 production. Nat. Med. 15(1), 42-49 (2009).

" Landmark publication demonstrating MSC potential in host defense.

88 Muller I, Vaegler M, Holzwarth C et al. Secretion of angiogenic proteins by human multipotent mesenchymal stromal cells and their clinical potential in the treatment of avascular osteonecrosis. Leukemia 22(11), 2054-2061 (2008).

89 Maggini J, Mirkin G, Bognanni I et al. Mouse bone marrow-derived mesenchymal stromal cells turn activated macrophages into a regulatory-like profile. PLoS ONE 5(2), e9252 (2010).

90 Napoli I, Neumann H. Protective effects of microglia in multiple sclerosis. Exp. Neurol. 225(1), 24-28 (2010).

91 Keimpema E, Fokkens MR, Nagy Z et al. Early transient presence of implanted bone marrow stem cells reduces lesion size after cerebral ischaemia in adult rats. Neuropathol. Appl. Neurobiol. 35(1), 89-102 (2009).

92 Lee JK, Jin HK, Bae JS. Bone marrow-derived mesenchymal stem cells reduce brain amyloid-beta deposition and accelerate the activation of microglia in an acutely induced Alzheimer's disease mouse model. Neurosci. Lett. 450(2), 136-141 (2009).

93 Iacobaeus E, Amoudruz P, Strom M et al. The expression of VEGF-A is down regulated in peripheral blood mononuclear cells of patients with secondary progressive multiple sclerosis. PLoS ONE 6(5), e19138 (2011).

94 Mahad D, Planchon SM, Cohen JA. Mesenchymal stem cell transplantation to treat multiple sclerosis. In: Multiple Sclerosis Therapeutics (4th Edition). Cohen JA, Rudick RA (Eds). Cambridge University Press, Cambridge, UK, 520-534 (2011).

95 Connick P, Kolappan M, Crawley C et al. Autologous mesenchymal stem cells for the treatment of secondary progressive multiple sclerosis: an open-label Phase 2a proof-ofconcept study. Lancet Neurol. 11(2), 150-156 (2012).

96 Krampera M, Glennie S, Dyson J et al. Bone marrow mesenchymal stem cells inhibit the response of naive and memory antigen-specific $\mathrm{T}$ cells to their cognate peptide. Blood 101(9), 3722-3729 (2003). 
97 Le Blanc K, Tammik L, Sundberg B, Haynesworth SE, Ringden O. Mesenchymal stem cells inhibit and stimulate mixed lymphocyte cultures and mitogenic responses independently of the major histocompatibility complex. Scand. J. Immunol. 57(1), 11-20 (2003).

98 Beyth S, Borovsky Z, Mevorach D et al. Human mesenchymal stem cells alter antigen-presenting cell maturation and induce T-cell unresponsiveness. Blood 105(5), 2214-2219 (2005).

99 Klyushnenkova E, Mosca JD, Zernetkina V et al. $\mathrm{T}$ cell responses to allogeneic human mesenchymal stem cells: immunogenicity, tolerance, and suppression. J. Biomed. Sci. 12(1), 47-57 (2005).

100 Rasmusson I, Uhlin M, Le Blanc K, Levitsky V. Mesenchymal stem cells fail to trigger effector functions of cytotoxic T lymphocytes. J. Leukoc. Biol. 82(4), 887-893 (2007).

101 Djouad F, Pience P, Bony C et al. Immunosuppressive effect of mesenchymal stem cells favors tumor growth in allogeneic animals. Blood 102, 3837-3844 (2003).

102 Le Blanc K, Frassoni F, Ball L et al. Mesenchymal stem cells for treatment of steroid-resistant, severe, acute graft-versus-host disease: a Phase II study. Lancet 371, 1579-1586 (2008).

103 Kebriaei P, Isola L, Bahceci E et al. Adult human mesenchymal stem cells added to corticosteroid therapy for the treatment of acute graft-versus-host disease. Biol. Blood Marrow Transplant. 15(7), 804-811 (2009).

104 Hare JM, Traverse JH, Henry TD et al. A randomized, double-blind, placebo-controlled, dose-escalation study of intravenous adult human mesenchymal stem cells (prochymal) after acute myocardial infarction. J. Am. Coll. Cardiol. 54(24), 2277-2286 (2009).

105 Liang J, Zhang H, Hua B et al. Allogenic mesenchymal stem cells transplantation in refractory systemic lupus erythematosus: a pilot clinical study. Ann. Rheum. Dis. 69(8), 1423-1429 (2010).

106 Horwitz EM, Prockop DJ, Fitzpatrick LA et al. Transplantability and therapeutic effects of bone marrow-derived mesenchymal cells in children with osteogenesis imperfecta. Nat. Med. 5(3), 309-313 (1999).

107 Horwitz EM, Prockop DJ, Gordon PL et al. Clinical responses to bone marrow transplantation in children with severe osteogenesis imperfecta. Blood 97(5), 1227-1231 (2001).

108 Koc ON, Day J, Nieder M, Gerson SL, Lazarus HM, Krivit W. Mesenchymal stem cells. Allogeneic mesenchymal stem cell infusion for treatment of metachromatic leukodystrophy (MLD) and Hurler syndrome (MPS-IH). Bone Marrow Transplant. 30, 215-222 (2002).

109 Cahill RA, Jones OY, Klemperer M et al. Replacement of recipient stromal/mesenchymal cells after bone marrow transplantation using bone fragments and cultured osteoblast-like cells. Biol. Blood Marrow Transplant. 10(10), 709-717 (2004).

110 Ho AD, Wagner W, Franke W. Heterogeneity of mesenchymal stromal cell preparations. Cytotherapy 10, 320-330 (2008).

111 Agashi K, Chau DYS, Shakesheff KM. The effect of delivery via narrow-bore needles on mesenchymal cells. Regen. Med. 4, 49-64 (2009).

112 Bacigalupo A, Valle M, Podesta M et al. T-cell suppression mediated by mesenchymal stem cells is deficient in patients with severe aplastic anemia. Exp. Hematol. 33, 819-827 (2005).

113 Murphy JM, Dixon K, Beck S, Fabian D, Feldman A, Barry F. Reduced chondrogenic and adipogenic activity of mesenchymal stem cells from patients with advanced osteoarthritis. Arthritis Rheum. 46, 704-713 (2002).

114 Del Papa N, Quirici N, Soligo D et al. Bone marrow endothelial progenitors are defective in systemic sclerosis. Arthritis Rheum. 54, 2605-2615 (2006).

115 Kastrinaki MC, Sidiropoulos P, Roche S et al. Functional, molecular and proteomic characterisation of bone marrow mesenchymal stem cells in rheumatoid arthritis. Ann. Rheum. Dis. 67, 741-749 (2008).

116 Bocelli-Tyndall C, Bracci L, Spagnoli G et al. Bone marrow mesenchymal stromal cells (BM-MSCs) from healthy donors and auto-immune disease patients reduce the proliferation of autologous- and allogeneic-stimulated lymphocytes in vitro. Rheumatology 46, 403-408 (2007).

117 Larghero J, Farge D, Braccini A et al. Phenotypical and functional characteristics of in vitro expanded bone marrow mesenchymal stem cells from patients with systemic sclerosis. Ann. Rheum. Dis. 67, 443-449 (2008).

118 Papadaki HA, Tsagournisakis M, Mastorodemos $\mathrm{V}$ et al. Normal bone marrow hematopoietic stem cell reserves and normal stromal cell function support the use of autologous stem cell transplantation in patients with multiple sclerosis. Bone Marrow Transplant. 36, 1053-1063 (2005).
119 Mallam E, Kemp K, Wilkins A, Rice C, Scolding N. Characterization of in vitro expanded bone marrow-derived mesenchymal stem cells from patients with multiple sclerosis. Mult. Scler. 16, 909-918 (2010).

120 Mazzanti B, Aldinucci A, Biagioli T et al. Differences in mesenchymal stem cell cytokine profiles between MS patients and healthy donors: implications for assessment of disease activity and treatment. J. Neuroimmunol. 199, 142-150 (2008).

121 Chen-Plotkin AS, Vossel KA, Samuels MA, Chen MH. Encephalopathy, stroke and myocardial infarction with DMSO use in stem cell transplantation. Neurology 68, 859-861 (2007).

122 Sundin M, Ringden O, Sundberg B, Nava S, Gotherstrom C, Le Blanc K. No alloantibodies against mesenchymal stromal cells, but presence of anti-fetal calf serum antibodies, after transplantation in allogeneic hematopoietic stem cell recipients. Haematologia 92, 1208-1215 (2007).

123 Horwitz EM, Gordon PL, Koo WKK et al. Isolated allogeneic bone marrow-derived mesenchymal cells engraft and stimulate growth in children with osteogenesis imperfecta: implications for cell therapy of bone. Proc. Natl Acad. Sci. USA 99, 8932-8937 (2002).

124 Brooke G, Cook M, Blair C et al. Therapeutic applications of mesenchymal stromal cells. Semin. Cell Dev. Biol. 18, 846-858 (2007).

125 Le Blanc K, Ringden O. Immunomodulation by mesenchymal stem cells and clinical experience. J. Intern. Med. 262 (5), 509-525 (2007).

126 Sundin M, Orvell C, Rasmusson I, Sundberg B, Ringden O, Le Blanc K. Mesenchymal stem cells are susceptible to human herpesviruses, but viral DNA cannot be detected in the healthy seropositive individual. Bone Marrow Transplant. 37, 1051-1059 (2006).

127 Karlsson H, Samarasinghe S, Ball LM et al. Mesenchymal stem cells exert differential effects on alloantigen and virus-specific T-cell responses. Blood 112(3), 532-541 (2008).

128 Ringden O, Uzunel M, Rasmusson I et al. Mesenchymal stem cells for treatment of therapy-resistant graft-versus-host disease. Transplantation 81, 1390-1397 (2006).

129 Ning H, Yang F, Jiang M et al. The correlation between cotransplantation of mesenchymal stem cells and higher recurrence rate in hematologic malignancy patients: outcome of a pilot clinical study. Leukemia 22(3), 593-599 (2008). 
130 Prindull G, Zipori D. Environmental guidance of normal and tumor cell plasticity: epithelial mesenchymal transitions as a paradigm. Blood 103, 2892-2899 (2004).

131 Serakinci N, Guldberg P, Burns JS et al. Adult human mesenchymal stem cell as a target for neoplastic transformation. Oncogene 23, 5095-5098 (2004).

132 Greaves M. Molecular genetics, natural history and the demise of childhood leukaemia. Eur. J. Cancer 35, 1941-1953 (1999).

133 Houghton JM, Stoicov C, Nomura S et al. Gastric cancer originating from bone marrow-derived cells. Science 306, 1568-1571 (2004).

134 Tolar J, Nauta AJ, Osborn MJ et al. Sarcoma derived from cultured mesenchymal stem cells. Stem Cells 25(2), 371-379 (2007).

135 Bernardo ME, Zaffaroni N, Novara F et al. Human bone marrow-derived mesenchymal stem cells do not undergo transformation after long-term in vitro culture and do not exhibit telomere maintenance mechanisms. Cancer Res. 67, 9142-9149 (2007).

136 Breitbach M, Bostani T, Roell W et al. Potential risks of bone marrow cell transplantation into infarcted hearts. Blood 110, 1362-1369 (2007).

137 Wang Y, Huso DL, Harrington J et al. Outgrowth of a transformed cell population derived from normal human BM mesenchymal stem cell culture. Cytotherapy 7, 509-519 (2005).

138 Rubio D, Garcia-Castro J, Martin MC et al. Spontaneous human adult stem cell transformation. Cancer Res. 65, 3035-3039 (2005).

139 Kim J, Kang JW, Park JH et al. Biological characterization of long-term cultured human mesenchymal stem cells. Arch. Pharm. Res. 32, 117-126 (2008).

140 Rosland GV, Svendsen A, Torsvik A et al. Long-term cultures of bone marrow-derived human mesenchymal stem cells frequently undergo spontaneous malignant transformation. Cancer Res. 69, 5331-5339 (2009).

141 Kidd S, Spaeth E, Klopp A, Andreff M, Hall $\mathrm{B}$, Marini FC. The (in) auspicious role of mesenchymal stromal cells in cancer: be it friend or foe. Cytotherapy 10, 657-667 (2008).

142 Tabe Y, Konopleva M, Munsell MF et al. PML-RAR $\alpha$ is associated with leptinreceptor induction: the role of mesenchymal stem cell-derived adipocytes in APL survival. Blood 103, 1815-1822 (2004).

143 Karnoub AE, Dash AB, Vo AP et al. Mesenchymal stem cells within tumour stroma promote breast cancer metastasis. Nature 449, 557-565 (2007).

144 Le Blanc K, Samuelsson H, Gustafsson B et al. Transplantation of mesenchymal stem cells to enhance engraftment of hematopoietic stem cells. Leukemia 21(8), 1733-1738 (2007)

145 Coles AJ, Fox E, Vladic A et al. Alemtuzumab more effective than interferon $\beta$-1a at 5-year follow-up of CAMMS223 clinical trial. Neurology 78(14), 1069-1078 (2012).

146 Liu ZJ, Zhuge Y, Velazquez OC. Trafficking and differentiation of mesenchymal stem cells. J. Cell. Biochem. 106(6), 984-991 (2009).

147 Ruster B, Gottig S, Ludwig RJ et al. Mesenchymal stem cells display coordinated rolling and adhesion behavior on endothelial cells. Blood 108(12), 3938-3944 (2006).

148 Sackstein R, Merzaban JS, Cain DW et al. Ex vivo glycan engineering of CD44 programs human multipotent mesenchymal stromal cell trafficking to bone. Nat. Med. 14(2), 181-187 (2008).

149 Barkhof F, Rocca M, Francis G et al. Validation of diagnostic magnetic resonance imaging criteria for multiple sclerosis and response to interferon $\beta 1$ a. Ann. Neurol. 53, 718-724 (2003).

150 Tintore M, Rovira M, Rio J et al. New diagnostic criteria for multiple sclerosis. Application in first demyelinating episode. Neurology 60, 27-30 (2003).

151 Caimi PF, Reese J, Lee Z, Lazarus HM. Emerging therapeutic approaches for multipotent mesenchymal stromal cells. Curr. Opin Hematol. 17(6), 505-513 (2010).

152 Mendez-Ferrer S, Michurina TV, Ferraro F et al. Mesenchymal and haematopoietic stem cells form a unique bone marrow niche. Nature 466(7308), 829-834 (2010).

" - Hallmark publication defining the role of MSCs in hematopoietic stem cell homing and regulation.

153 Lazarus HM, Koc ON, Devine SM et al. Cotransplantation of HLA-identical sibling culture-expanded mesenchymal stem cells and hematopoietic stem cells in hematologic malignancy patients. Biol. Blood Marrow Transplant. 11(5), 389-398 (2005).

154 Koc ON, Gerson SL, Cooper BW et al. Rapid hematopoietic recovery after coinfusion of autologous-blood stem cells and culture-expanded marrow mesenchymal stem cells in advanced breast cancer patients receiving high-dose chemotherapy. J. Clin. Oncol. 18(2), 307-316 (2000).

155 Prinz M, Garbe F, Schmidt $\mathrm{H}$ et al. Innate immunity mediated by TLR9 modulates pathogenicity in an animal model of multiple sclerosis. J. Clin. Invest. 116(2), 456-464 (2006).

156 Marta M, Andersson A, Isaksson M, Kampe O, Lobell A. Unexpected regulatory roles of TLR4 and TLR9 in experimental autoimmune encephalomyelitis. Eur. J. Immunol. 38(2), 565-575 (2008).

157 Bsibsi M, Ravid R, Gveric D, van Noort JM. Broad expression of Toll-like receptors in the human central nervous system. J. Neuropathol. Exp. Neurol. 61(11), 1013-1021 (2002).

158 Reynolds JM, Pappu BP, Peng J et al. Toll-like receptor 2 signaling in $\mathrm{CD}^{(+)}$ $\mathrm{T}$ lymphocytes promotes $\mathrm{T}$ helper 17 responses and regulates the pathogenesis of autoimmune disease. Immunity 32(5), 692-702 (2010).

159 Waldner H, Collins M, Kuchroo VK. Activation of antigen-presenting cells by microbial products breaks self tolerance and induces autoimmune disease. J. Clin. Invest. 113(7), 990-997 (2004).

160 Hwa Cho H, Bae YC, Jung JS. Role of Toll-like receptors on human adiposederived stromal cells. Stem Cells 24(12), 2744-2752 (2006).

161 Lombardo E, DelaRosa O, ManchenoCorvo P, Menta R, Ramirez C, Buscher D. Toll-like receptor-mediated signaling in human adipose-derived stem cells: implications for immunogenicity and immunosuppressive potential. Tissue Eng. Part A 15(7), 1579-1589 (2009).

162 Liotta F, Angeli R, Cosmi L et al. Toll-like receptors 3 and 4 are expressed by human bone marrow-derived mesenchymal stem cells and can inhibit their T-cell modulatory activity by impairing notch signaling. Stem Cells 26(1), 279-289 (2008).

163 Kerfoot SM, Long EM, Hickey MJ et al. TLR4 contributes to disease-inducing mechanisms resulting in central nervous system autoimmune disease. J. Immunol. 173(11), 7070-7077 (2004).

164 Ichikawa HT, Williams LP, Segal BM. Activation of APCs through CD 40 or Toll-like receptor 9 overcomes tolerance and precipitates autoimmune disease. J. Immunol. 169(5), 2781-2787 (2002).

165 Tigno-Aranjuez JT, Jaini R, Tuohy VK, Lehmann PV, Tary-Lehmann M. Encephalitogenicity of complete Freund's adjuvant relative to $\mathrm{CpG}$ is linked to induction of Th17 cells. J. Immunol. 183(9), 5654-5661 (2009).

166 Moyeddin Bonab M, Yazdanbakhsh S, Loft $\mathrm{J}$ et al. Does mesenchymal stem cell therapy help multiple sclerosis patients? Iran. J. Immunol. 4, 50-57 (2007). 
167 Liang J, Zhang H, Hua B et al. Allogeneic mesenchymal stem cells transplantation in treatment of multiple sclerosis. Mult. Scler. 15, 644-646 (2009).

168 Riordan NH, Ichim TE, Min W-P et al. Non-expanded adipose stromal vascular fraction cell therapy for multiple sclerosis. J. Transl Med. 7, 29 (2009).

169 Karussis D, Karageorgiou C, Vaknin-Dembinsky A et al. Safety and immunologic effects of mesenchymal stem cell transplantation in patients with multiple sclerosis and amyotrophic lateral sclerosis. Arch. Neurol. 67, 1187-1194 (2010).

170 Yamout B, Hourani R, Salti H et al. Bone marrow mesenchymal stem cell transplantation in patients with multiple sclerosis: a pilot study. J. Neuroimmunol. 227, 185-189 (2010)

171 Rice CM, Whone AL, Marks DI, Butler S, Brooks DJ, Scolding NJ. A safety and feasibility study of intravenous autologous bone marrow stem cells in multiple sclerosis. J. Neurol. Neurosurg. Psychiatry 78, 1036 (2007).
172 Scolding N, Marks D, Rice C. Autologous mesenchymal bone marrow stem cells: practical considerations. J. Neurol. Sci. 265, 111-115 (2008).

\section{Website}

201 Autologous Mesenchymal Stem Cell (MSC) Transplantation in MS. http://clinicaltrials.gov/ct2/show/ NCT00813969 